\title{
The Generalized Transmuted Weibull Distribution for Lifetime Data
}

\author{
Zohdy M. Nofal \\ Department of Statistics, Mathematics and Insurance, Benha University, Egypt \\ dr.zohdynofal@fcom.bu.edu.eg \\ Yehia M. El Gebaly \\ Department of Statistics, Mathematics and Insurance, Benha University, Egypt \\ yehia1958@yahoo.com
}

\begin{abstract}
A new lifetime model, which extends the Weibull distribution using the generalized transmuted-G family proposed by Nofal et al. (2017), called the generalized transmuted Weibull distribution is proposed and studied. Various of its structural properties are derived. The maximum likelihood method is used to estimate the model parameters. A small simulation study is conducted. The new distribution is applied to a real data set to illustrate its flexibility. It can serve as an alternative model to other lifetime models available in the literature for modeling positive real data in many areas.
\end{abstract}

Keywords: Generalized Transmuted-G Family, Order Statistics, Probability Weighted Moments, Maximum Likelihood, Moments.

\section{Introduction}

There has been an increased interest among statisticians to develop new methods for generating new families of distributions because there is a persistent need for extending the classical forms of the well-known distributions to be more capable for modeling data in different areas such as lifetime analysis, engineering, economics, finance, demography, actuarial and biological and medical sciences.

Many authors constructed new generators. for instance, Zografos and Balakrishanan (2009) proposed the gamma-G type 1, Cordeiro and de Castro (2011) studied the Kumaraswamy-G, Alexander et al. (2012), introduced the McDonald-G, Bourguignon et al. (2014) defined the Weibull-G, Afify et al. (2017) proposed the beta transmuted-G and Nofal et al. (2017) defined and studied the generalized transmuted-G families.

The Weibull distribution is the most popular distribution in the literature for analyzing lifetime data. However, its major drawback is that its hazard rate cannot accommodate nonmonotone hazard rates (especially, bathtub shaped hazard rates and unimodal failure rate). The data with bathtub-shaped and unimodal failure rate function are quite common in reliability and biological studies. So, many generalizations of the Weibull distribution have been proposed and studied to cope with bathtub-shaped failure rates.

Among these models, we refer to the additive Weibull (Xie and Lai, 1995), exponentiated Weibull (Mudholkar et al., 1995, 1996), extended Weibull (Xie et al., 2002), modified Weibull (Lai et al., 2003), beta modified Weibull (Silva et al., 2010), Kumaraswamy Weibull (Cordeiro et al., 2012), transmuted Weibull (Aryal and Tsokos, 2011), Kumaraswamy modified Weibull (Cordeiro et al., 2012), transmuted complementary 
Weibull geometric (Afify et al., 2014) and Kumaraswamy complementary Weibull geometric (Afify et al., 2016) distributions.

In particular, the two parameter Weibull (W) distribution with probability density function (pdf) and cumulative distribution function (cdf) are given (for $x \geq 0$ ) by

$$
g(x)=\beta \alpha^{\beta} x^{\beta-1} e^{-(\alpha x)^{\beta}} \text { and } G(x)=1-e^{-(\alpha x)^{\beta}},
$$

respectively, where $\alpha>0$ is a shape parameter and $\beta>0$ is a scale parameter.

In this paper, we define and study a new lifetime model called the generalized transmuted Weibull (GT-W) distribution. Its main feature is that two additional shape parameters are inserted in (1) to provide greater flexibility for the generated distribution. Based on the generalized transmuted $-G(\mathrm{GT}-\mathrm{G})$ family of distributions, we construct the new five-parameter GT-W model and give a comprehensive description of some of its mathematical properties hoping that it will attract wider applications in engineering, survival and lifetime data, reliability and other areas of research.

Let $g(x ; \xi)$ and $G(x ; \xi)$ denote the density and cumulative functions of the baseline model with parameter vector $\xi$. Nofal et al. (2017) defined the cdf of their GT-G family by

$$
F(x ; \lambda, a, b, \xi)=G(x ; \xi)^{a}\left\{1+\lambda-\lambda G(x ; \xi)^{b}\right\}
$$

The pdf of the GT-G family is given by

$$
f(x ; \lambda, a, b, \xi)=g(x ; \xi) G(x ; \xi)^{a-1}\left\{a(1+\lambda)-\lambda(a+b) G(x ; \xi)^{b}\right\} .
$$

Henceforth, let $\mathrm{G}$ be a continuous baseline distribution. We define the GT-G distribution with two extra parameters $a$ and $b$ by the pdf (3). A random variable $X$ with pdf (3) is denoted by $X \sim \mathrm{GT}-\mathrm{G}(\lambda, a, b, \xi)$. If $a=b=1$, it corresponds to the transmuted class (TC) studied by Shaw and Buckley (2007). If $a=1$ and $b=0$, the GT-G family reduces to the exponentiated-G (E-G) family defined by Gupta et al. (1998) and finally the GT-G family reduces to the baseline distribution when $a=b=1$ and $\lambda=0$.

Let $T$ be a random variable having the EW distribution with positive parameters $\alpha, \beta$ and $\delta$. Then the pdf and cdf of $T$ are given by

$$
g(t)=\delta \beta \alpha^{\beta} t^{\beta-1} e^{-(\alpha t)^{\beta}}\left[1-e^{-(\alpha t)^{\beta}}\right]^{\delta-1} \text { and } G(t)=\left[1-e^{-(\alpha t)^{\beta}}\right]^{\delta} .
$$

For any $n>-\beta$, the $n$th ordinary and incomplete moments of $T$ are given by $\mu_{n}^{\prime}=\sum_{j=0}^{\infty} \omega_{j} \delta \alpha^{-n} \Gamma(1+n / \beta) \quad$ and $\varphi_{n}(t)=\sum_{j=0}^{\infty} \omega_{j} \delta \alpha^{-n} \gamma\left(1+n / \beta,(\alpha / t)^{\beta}\right)$, respectively, where ${ }_{\delta} \omega_{j}=\frac{(-1)^{j} \Gamma(\delta)}{j ! \Gamma(\delta-j)(j+1)^{(n+\beta) / \beta}}$.

For further information about the EW distribution we refer to Mudholkar and Srivastava (1993), Mudholkar and Hutson (1996) and Nadarajah and Kotz (2006). 
The rest of the paper is outlined as follows. In Section 2, we define the GT-W distribution, provide its sub-models and give some plots for its pdf and hazard rate function (hrf ). We derive useful mixture representations for the pdf and cdf in Section 3. We provide in Section 4 some mathematical properties of the GT-W distribution including ordinary and incomplete moments, moments of the residual life, reversed residual life, quantile function (qf ), moment generating function (mgf ), Rényi and qentropies and order statistics. The maximum likelihood estimates (MLEs) of the unknown parameters are obtained in Section 5. The simulation results to assess the performance of the proposed maximum likelihood estimation procedure are discussed in Section 6. In Section 7, the GT-W distribution is applied to a real data set to illustrate its potentiality. Finally, in Section 8, we provide some concluding remarks.

\section{The GT-W distribution}

By inserting the cdf in (1) in equation (2) and omitting the dependence on the parameters $\alpha, \beta, \lambda, a, b$, we obtain the cdf of the five-parameter GT-W model (for $x>0$ )

$$
F(x)=\left[1-e^{-(\alpha x)^{\beta}}\right]^{a}\left\{1+\lambda-\lambda\left[1-e^{-(\alpha x)^{\beta}}\right]^{b}\right\}
$$

The corresponding pdf of (4) is given by

$$
\mathrm{f}(\mathrm{x})=\beta \alpha^{\beta} \mathrm{x}^{\beta-1} \mathrm{e}^{-(\alpha \mathrm{x})^{\beta}}\left[1-\mathrm{e}^{-(\alpha \mathrm{x})^{\beta}}\right]^{\mathrm{a}-1} \times\left\{\mathrm{a}(1+\lambda)-\lambda(\mathrm{a}+\mathrm{b})\left[1-\mathrm{e}^{-(\alpha \mathrm{x})^{\beta}}\right]^{\mathrm{b}}\right\},
$$

where $\alpha, \beta, a$ and $b$ are positive parameters and $|\lambda| \leq 1$. Here, $\beta$ is a scale parameter representing the characteristic life, $\alpha, a$ and $b$ are shape parameters representing the different patterns of the GT-W distribution and $\lambda$ is the transmuted parameter. We denote a random variable $X$ having pdf (5) by $X \sim \operatorname{GT}-\mathrm{W}(\alpha, \beta, \lambda, a, b, x)$. The reliability function (rf), hrf, reversid hazard rate function (rhrf) and cumulative hazard rate function (chrf) of $X$ are given by

$$
\begin{aligned}
& R(x)=1-\left[1-e^{-(\alpha x)^{\beta}}\right]^{a}\left\{1+\lambda-\lambda\left[1-e^{-(\alpha x)^{\beta}}\right]^{b}\right\} \\
& h(x)=\frac{\beta \alpha^{\beta} x^{\beta-1} e^{-(\alpha x)^{\beta}}\left[1-e^{-(\alpha x)^{\beta}}\right]^{a-1}\left\{a(1+\lambda)-\lambda(a+b)\left[1-e^{-(\alpha x)^{\beta}}\right]^{b}\right\}}{\left[1-\left[1-e^{-(\alpha x)^{\beta}}\right]^{a}\left\{1+\lambda-\lambda\left[1-e^{-(\alpha x)^{\beta}}\right]^{b}\right\}\right]}, \\
& \tau(x)=\frac{\beta \alpha^{\beta} x^{\beta-1} e^{-(\alpha x)^{\beta}}\left[1-e^{-(\alpha x)^{\beta}}\right]^{a-1}\left\{a(1+\lambda)-\lambda(a+b)\left[1-e^{-(\alpha x)^{\beta}}\right]^{b}\right\}}{\left[1-e^{-(\alpha x)^{\beta}}\right]^{a}\left\{1+\lambda-\lambda\left[1-e^{-(\alpha x)^{\beta}}\right]^{b}\right\}}
\end{aligned}
$$

and

$H(x)=-\ln \left[1-\left[1-e^{-(\alpha x)^{\beta}}\right]^{a}\left\{1+\lambda-\lambda\left[1-e^{-(\alpha x)^{\beta}}\right]^{b}\right\}\right]$,

respectively. 
Asymptotics of the cdf, pdf and hrf of the GTW distribution as $x \rightarrow 0$ are given by

$$
\begin{aligned}
& F(x) \sim(1+\lambda)(\alpha x)^{a \beta}, \\
& f(x) \sim a \beta(1+\lambda) \alpha^{\beta} x^{a \beta-1}, \\
& h(x) \sim a \beta(1+\lambda) \alpha^{\beta} x^{a \beta-1} .
\end{aligned}
$$

The asymptotics of TGW distribution from cdf, pdf and hrf as $x \rightarrow \infty$ are given by

$$
\begin{aligned}
& 1-F(x) \sim b \lambda e^{-(\alpha x)^{\beta},} \\
& f(x) \sim b \lambda \beta \alpha^{\beta} x^{\beta-1} e^{-(\alpha x)^{\beta},} \\
& h(x) \sim \beta \alpha^{\beta} x^{\beta-1} .
\end{aligned}
$$

Table 1: Sub-models of the GT-W model

\begin{tabular}{|c|c|c|c|c|c|c||}
\hline Model & $\alpha$ & $\beta$ & $\lambda$ & $a$ & $b$ & Author \\
\hline$G T-R$ & $\alpha$ & 2 & $\lambda$ & $a$ & $b$ & New \\
\hline \hline$G T-E$ & $\alpha$ & 1 & $\lambda$ & $a$ & $b$ & New \\
\hline$T W$ & $\alpha$ & $\beta$ & $\lambda$ & 1 & 1 & Aryal and Tsokos (2011) \\
\hline \hline$T E$ & $\alpha$ & 1 & $\lambda$ & 1 & 1 & Merovci (2013) \\
\hline \hline$T R$ & $\alpha$ & 2 & $\lambda$ & 1 & 1 & Kundu and Raqab (2005) \\
\hline$E W$ & $\alpha$ & $\beta$ & 0 & $a$ & 0 & Mudholkar and Srivastave (1993) \\
\hline$E R$ & $\alpha$ & 2 & 0 & $a$ & 0 & Gupta and Kundu (2001) \\
\hline$E E$ & $\alpha$ & 1 & 0 & $a$ & 0 & Weibull (1951) \\
\hline \hline$W$ & $\alpha$ & $\beta$ & 0 & 1 & 1 & Rayleigh (1880) \\
\hline \hline$E$ & $\alpha$ & 2 & 0 & 1 & 1 & 1 \\
\hline \hline$E$ & $\alpha$ & 1 & 0 & 1 & 1 & \\
\hline \hline
\end{tabular}

The plots of the GT-W density for some parameter values $\alpha, \beta, \lambda, a$ and $b$ are displayed in Figure 1. Figure 2 provides some plots of the hrf of the GT-W model for selected parameter values. 

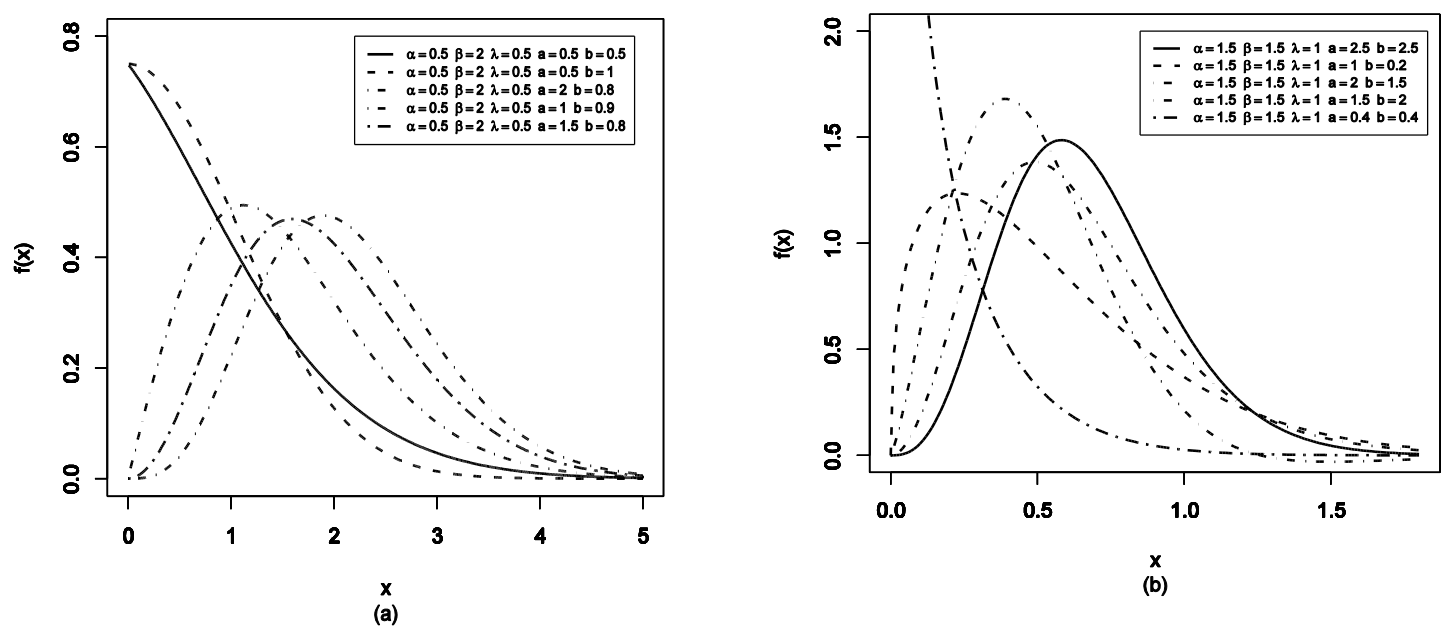

Figure 1: Plots of the GT-W density function for some parameter values.
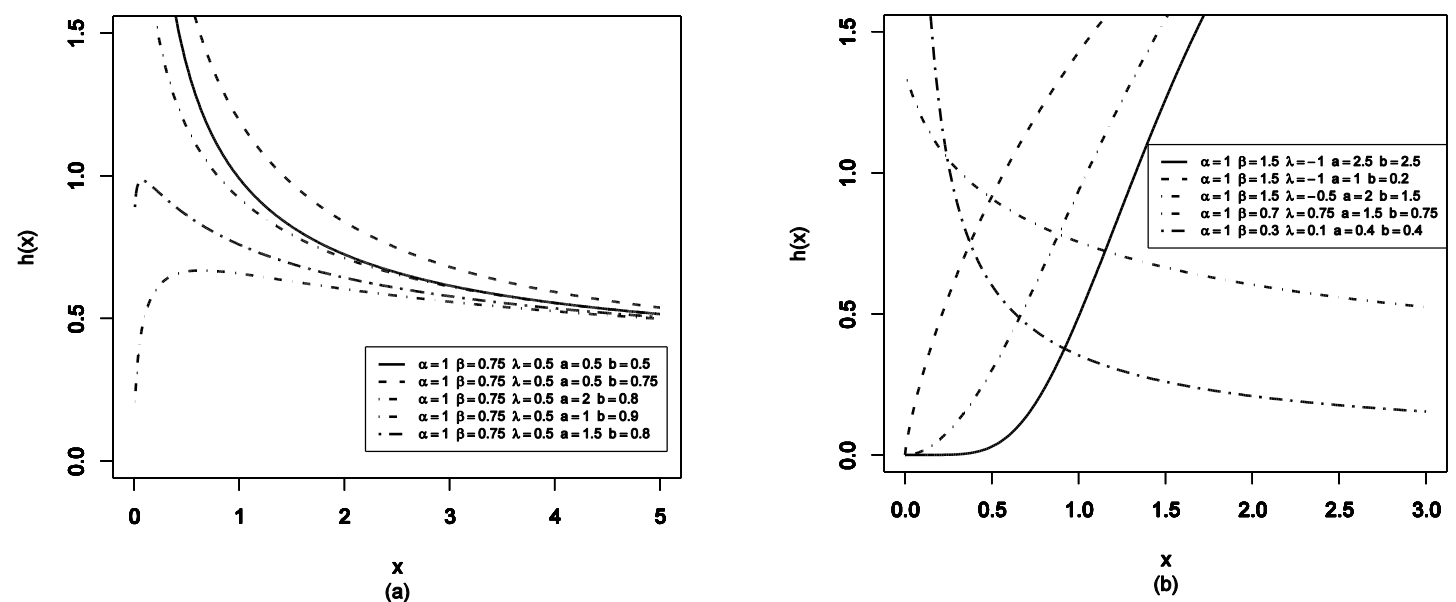

Figure 2: Plots of the GT-W hazard rate function for some parameter values

\section{Mixture representation}

The GT-W density function (5) can be expressed as

$$
f(x)=a(1+\lambda) g(x) G(x)^{a-1}-\lambda(a+b) g(x) G(x)^{a+b-1} .
$$

By inserting (1) in equation (6), we obtain

$$
\begin{aligned}
f(x)= & a(1+\lambda) \beta \alpha^{\beta} x^{\beta-1} e^{-(\alpha x)^{\beta}}\left[1-e^{-(\alpha x)^{\beta}}\right]^{a-1} \\
& -\lambda(a+b) \beta \alpha^{\beta} x^{\beta-1} e^{-(\alpha x)^{\beta}}\left[1-e^{-(\alpha x)^{\beta}}\right]^{a+b-1} .
\end{aligned}
$$


So, the GT-W density can be expressed as a mixture of two E-G densities, the first with power parameter $a$ and the seconed with power parameter $(a+b)$. Therefore, equation (7) can be expressed as

$$
f(x)=(1+\lambda) h_{a}(x)-\lambda h_{a+b}(x),
$$

where $h_{a}(x)$ is the EW density function with power parameter $a$, scale parameter $\alpha$ and shape parameter $\beta$. then, the GT-W density can be expressed as a mixture of the EW densities and then several of its structural properties can be obtained from (8) and those properties of the EW distribution.

Similarly, the cdf (4) of $X$ can be expressed in the mixture form

$$
F(x)=f(x)=(1+\lambda) H_{a}(x)-\lambda H_{a+b}(x),
$$

where $H_{a}(x)$ is the EW cdf with power parameter $a$, scale parameter $\alpha$ and shape parameter $\beta$.

\section{Mathematical properties}

Here, we investigate mathematical properties of the GT-W distribution including ordinary and incomplete moments, moment of the residual life, moment of the reversid residual life, quantile function, mgf and Rényi and q-entropies, order statistics and some characterizations.

\subsection{Moments}

The $n$th ordinary moment of $X$ is given by

$$
\mu_{n}^{\prime}=E\left(X^{n}\right)=(1+\lambda) E\left(Y_{a}^{n}\right)-\lambda E\left(Y_{a+b}^{n}\right),
$$

where

$$
E\left(Y_{j}^{n}\right)=\int_{0}^{\infty} x^{n} h_{j}(x) d x, j=a, a+b .
$$

Therefore, for $n>-\beta$, we obtain

$$
\mu_{n}^{\prime}=\sum_{j=0}^{\infty} \omega_{j} \frac{(1+\lambda) a}{\alpha^{n}} \Gamma\left(1+\frac{n}{\beta}\right)-\sum_{j=0}^{\infty}{ }_{a+b} \omega_{j} \frac{\lambda(a+b)}{\alpha^{n}} \Gamma\left(1+\frac{n}{\beta}\right),
$$

where

$$
{ }_{a} \omega_{j}=\frac{(-1)^{j} \Gamma(a)}{j ! \Gamma(a-j)(j+1)^{(n+\beta) / \beta}} \text { and }{ }_{a+b} \omega_{j} \text { can be defined similarly. }
$$

Setting $n=1$ in (9), we have the mean of $X$. The skewness and kurtosis measures can be calculated from the ordinary moments using well-known relationships.

The $n$th central moment of $X$, say $M_{n}$, follows as

$$
M_{n}=E(X-\mu)^{n}=\sum_{k=0}^{n}(-1)^{k}\left(\begin{array}{l}
n \\
k
\end{array}\right)\left(\mu_{1}^{\prime}\right)^{n} \mu_{n-k}^{\prime} .
$$


The mean, variance, skewness and kurtosis plots of the GT-W are given in Figures 3 and 4 , respectively. These plots indicate that the GT-W distribution can model various data types in terms of skewness and kurtosis.

Table 2 provides numerical values for the mean, variance, skewness and kurtosis of $X$ for selected parameter values to illustrate their effects on these measures.
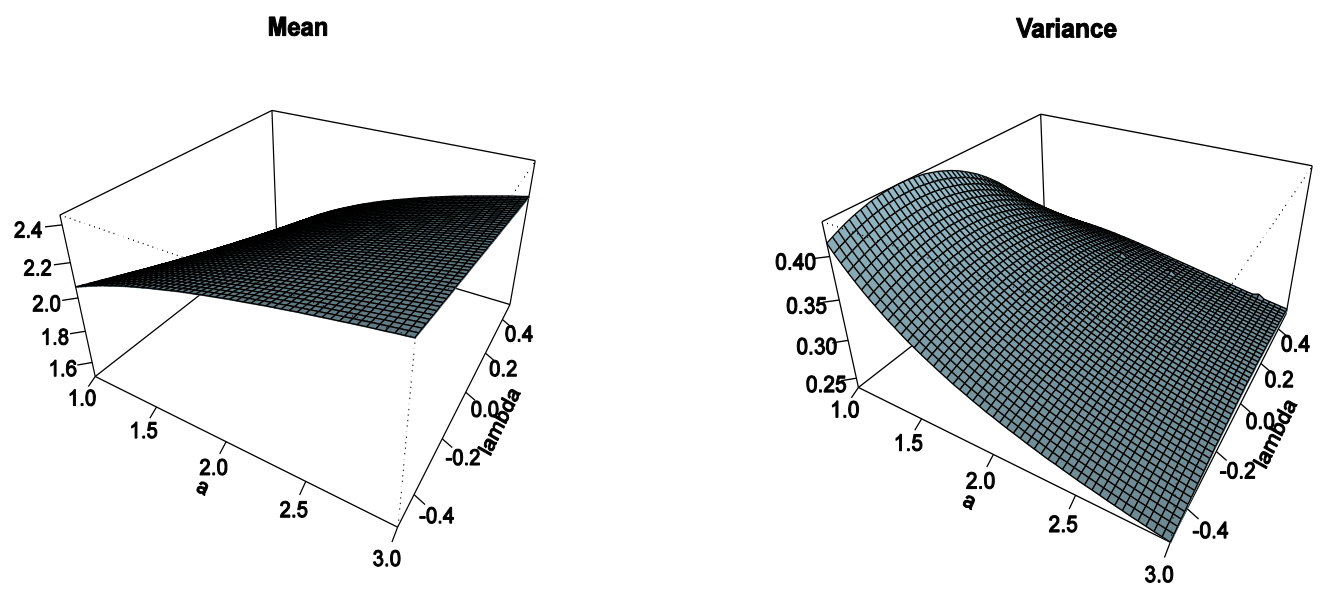

Figure 3: Plots of mean and variance of the GT-W distribution for several values of parameters
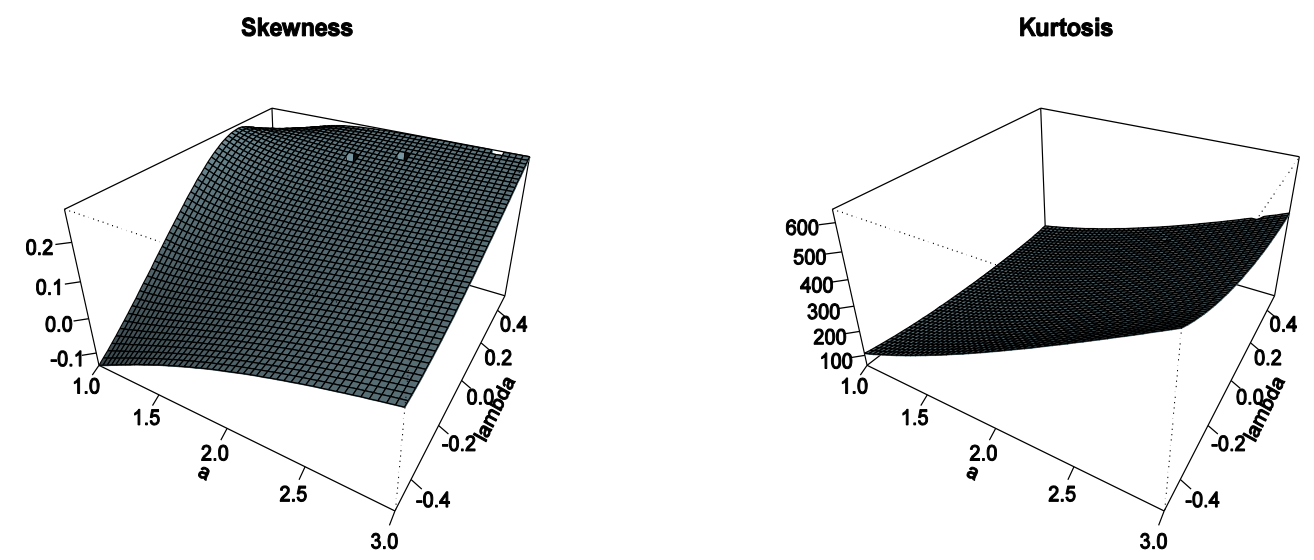

Figure 4: Plots of skewness and kurtosis of the GT-W distribution for several values of parameters 


\subsection{Incomplete moments}

The $n$th incomplete moment, say $\varphi_{n}(t)$ of the GT-W distribution is given by $\varphi_{n}(t)=$ $\int_{0}^{t} x^{n} f(x) d x$.

We can write from equation (8)

$$
\varphi_{n}(t)=(1+\lambda) \int_{0}^{t} x^{n} h_{a}(x) d x-\lambda \int_{0}^{t} x^{n} h_{a+b}(x) d x,
$$

and then using the lower incomplete gamma function, we obtain (for $n>-\beta$ )

$$
\varphi_{n}(t)=\sum_{j=0}^{\infty} \omega_{j} \gamma(s, z) \frac{(1+\lambda) a}{\alpha^{n}}-\sum_{j=0}^{\infty} \omega_{a+b} \gamma(s, z) \frac{\lambda(a+b)}{\alpha^{n}},
$$

where $s=1+n / \beta, \quad z=(\alpha / t)^{\beta}$ and $\gamma(s, z)=\int_{0}^{z} y^{s-1} e^{-y} d y$ is the the lower incomplete gamma function.

The important application of the first incomplete moment is related to the Lorenz and Bonferroni curves. These curves are very useful in economics, reliability, demography, insurance and medicine. The answers to many important questions in economics require more than just knowing the mean of the distribution, but its shape as well. The Lorenz, say $L_{F}(x)$, and Bonferroni, say $B[F(x)]$ curves are respectively defined (see Oluyede and Rajasooriya, 2013) by

$$
L_{F}(x)=\frac{1}{E(X)} \int_{0}^{x} t f(t) d t
$$

and

$$
B[F(x)]=\frac{1}{E(X) F(x)} \int_{0}^{x} t f(t) d t=\frac{L_{F}(x)}{F(x)} .
$$

Another application of the first incomplete moment is related to the mean residual life and the mean waiting time given by $m_{1}(t)=\left[1-\varphi_{1}(t)\right] / R(t)-t$ and $M_{1}(t)=t-$ $\varphi_{1}(t) / F(t)$, respectively.

Table 2: Mean, variance, skewness and kurtosis for selected parameter values with $\alpha=1$.

\begin{tabular}{|c|c|c|l|l|l|l|l|}
\hline \hline$\lambda$ & $a$ & $b$ & $\beta$ & mean & variance & skewness & kurtosis \\
\hline-1 & 1.5 & 0.75 & 1.5 & 1.2947 & 0.3764 & 0.8419 & 3.9857 \\
\hline & & & 2 & 1.1885 & 0.1817 & 0.4999 & 3.2626 \\
\hline & & & 5 & 1.0543 & 0.0246 & -0.1443 & 3.0051 \\
\hline \hline-0.5 & 1.5 & 0.75 & 1.5 & 3.3103 & 32.7140 & 5.2314 & 56.2768 \\
\hline & & & 2 & 1.1139 & 0.1964 & 0.4771 & 3.1959 \\
\hline & & & 5 & 1.0229 & 0.0297 & -0.2563 & 3.0947 \\
\hline \hline 0.5 & 1.5 & 0.75 & 1.5 & 2.2776 & 21.9729 & 6.3056 & 80.2666 \\
\hline & & & 2 & 0.9649 & 0.1925 & 0.6450 & 3.3869 \\
\hline & & & 5 & 0.9599 & 0.0339 & -0.1385 & 2.9109 \\
\hline 1 & 1.5 & 0.75 & 1.5 & 1.7612 & 15.8025 & 7.2935 & 107.3615 \\
\hline & & & 2 & 0.8903 & 0.1739 & 0.7541 & 3.6835 \\
\hline & & & 5 & 0.9285 & 0.0331 & -0.0689 & 2.9446 \\
\hline \hline
\end{tabular}




\subsection{Residual life function}

The $n$th moment of the residual life, say $m_{n}(t)=E\left[(X-t)^{n} \mid X>t\right], n=1,2, \ldots$, uniquely determine $F(x)$ (see Navarro et al., 1998). The $n$th moment of the residual life of $X$ is given by

$$
m_{n}(t)=\frac{1}{R(t)} \int_{t}^{\infty}(x-t)^{n} d F(x)
$$

Therefore, we ca write (for $n>-\beta$ )

$$
m_{n}(t)=\sum_{r=0}^{n} \frac{s_{r}}{R(t)}\left\{\sum_{j=0}^{\infty} \omega_{j} \gamma(s, z) \frac{(1+\lambda) a}{\alpha^{n}}-\sum_{j=0}^{\infty} \omega_{j+b} \gamma(s, z) \frac{\lambda(a+b)}{\alpha^{n}}\right\}
$$

where $s_{r}=\frac{(-1)^{n-r} n ! t^{n-r}}{r ! \Gamma(n-r+1)}$ and $\gamma(s, z)=\int_{z}^{\infty} y^{s-1} e^{-y} d y$ is the the upper incomplete gamma function.

Another interesting function is the mean residual life (MRL) function or the life expectation at age $t$ defined by $m_{1}(t)=E[(X-t) \mid X>t]$, which represents the expected additional life length for a unit which is alive at age $t$. The MRL of $X$ can be obtained by setting $n=1$ in the last equation.

\subsection{Reversed residual life function}

The $n$th moment of the reversed residual life, say $M_{n}(t)$, uniquely determines $F(x)$ (Navarro et al., 1998). The $M_{n}(t)$ is defined by

$$
M_{n}(t)=E\left[(t-X)^{n} \mid X \leq t\right]=\frac{1}{F(t)} \int_{0}^{t}(t-x)^{n} d F(x),
$$

where $t>0$ and $n=1,2, \ldots$

Therefore, the $n$th moment of the reversed residual life of $X$, given that $n>-\beta$, becomes

$$
M_{n}(t)=\sum_{r=0}^{n} \frac{b_{r}}{F(t)}\left\{\sum_{j=0}^{\infty} \omega_{j} \gamma(s, z) \frac{(1+\lambda) a}{\alpha^{n}}-\sum_{j=0}^{\infty} \omega_{j+b} \gamma(s, z) \frac{\lambda(a+b)}{\alpha^{n}}\right\},
$$

where $b_{r}=(-1)^{r} n ! / r !(n-r)$ !. The mean reversed residual life, also called mean inactivity time (MIT) or mean waiting time (MWT), is given by $M_{1}(t)=E[(t-X) \mid X \leq$ $t]$, and it represents the waiting time elapsed since the failure of an item on condition that this failure had occurred in $(0, t)$. The MIT of $X$ can be obtained simply by setting $n=1$ in the above equation. For further information about the properties of the MIT, we refer to Kayid and Ahmad (2004) and Ahmad et al. (2005).

\subsection{Generating function}

Let $M_{a}(t)$ be the mgf of $Y_{a}$. Therefore, using (8) the mgf of $X$, say $M(t)=E\left(e^{t x}\right)$, is given by

$$
M(t)=(1+\lambda) M_{a}(x)-\lambda M_{a+b}(x)
$$


At first, we determine the mgf of (1). We can write this mgf as

$$
M(t ; \alpha, \beta)=\beta \alpha^{\beta} \int_{0}^{\infty} \exp (t x) x^{\beta-1} \exp \left\{-(\alpha x)^{\beta}\right\} d x .
$$

By expanding $\exp (t x)$ and calculating the integral, we have

$$
\begin{aligned}
M(t ; \alpha, \beta) & =\beta \alpha^{\beta} \sum_{k=0}^{\infty} \frac{t^{k}}{k !} \int_{0}^{\infty} x^{\beta+k-1} \exp \left\{-(\alpha x)^{\beta}\right\} d x \\
& =\sum_{k=0}^{\infty} \frac{t^{k} \alpha^{-k}}{k !} \Gamma\left(\frac{\beta+k}{\beta}\right),
\end{aligned}
$$

where the gamma function is well-defined for any non-integer $\beta$.

Consider the complex parameter Wright generalized hypergeometric function with $p$ numerator and $q$ denominator parameters defined by

$$
{ }_{p} \Psi_{q}\left[\begin{array}{l}
\left(\alpha_{1}, A_{1}\right), \ldots,\left(\alpha_{p}, A_{p}\right) \\
\left(\beta_{1}, B_{1}\right), \ldots,\left(\beta_{q}, B_{q}\right)
\end{array} ; z\right]=\sum_{n=0}^{\infty} \frac{\prod_{j=1}^{p} \Gamma\left(\alpha_{j}+A_{j} n\right)}{\prod_{j=1}^{q} \Gamma\left(\beta_{j}+B_{j} n\right)} \frac{z^{n}}{n !} .
$$

Then, we can write $M(t ; \alpha, \beta)$ as

$$
\mathrm{M}(\mathrm{t} ; \alpha, \beta)={ }_{1} \Psi_{0}\left[\begin{array}{l}
\left.\left(1,-\beta^{-1}\right) ; \frac{\mathrm{t}}{\alpha}\right] \\
-
\end{array}\right.
$$

Then, the mgf of $X \sim \mathrm{EW}$ with power parameter $\delta$ is given by

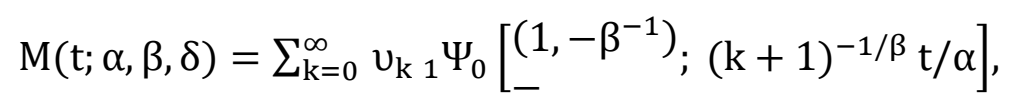

where $v_{k}=(-1)^{k} \Gamma(\delta+1) /(k+1) ! \Gamma(\delta-k)$.

Combining expressions (10) and (11), we obtain the mgf of $X$, say

$$
\begin{aligned}
& \mathrm{M}(\mathrm{t})=\sum_{\mathrm{k}=0}^{\infty} \frac{(-1)^{\mathrm{k}}}{(\mathrm{k}+1)_{1}} \Psi_{0}\left[\left(1,-\beta^{-1}\right) ;(\mathrm{k}+1)^{-1 / \beta} \mathrm{t} / \alpha\right] \\
& \times\left\{a(1+\lambda)\left(\begin{array}{l}
a-1 \\
k
\end{array}\right)-(a+b) \lambda\left(\begin{array}{l}
a+b-1 \\
k
\end{array}\right)\right\} .
\end{aligned}
$$

\subsection{Rényi and q-entropies}

The Rényi entropy of a random variable $X$ represents a measure of variation of the uncertainty. Then, the Rényi entropy of the GT-W distribution is given by

$$
I_{\theta}(X)=\frac{1}{1-\theta} \log \int_{-\infty}^{\infty} f(x)^{\theta} d x, \theta>0 \operatorname{and} \theta \neq 1
$$

By using the pdf in (5), we can write

$$
f(x)^{\theta}=(1+\lambda)^{\theta} h_{a}(x)^{\theta}\left\{1-L G(x)^{b}\right\}^{\theta}
$$




$$
\begin{gathered}
=\left[\mathrm{a} \beta \alpha^{\beta}(1+\lambda)\right]^{\theta} \mathrm{x}^{\theta(\beta-1)} \mathrm{e}^{-\theta(\alpha \mathrm{x})^{\beta}}\left[1-\mathrm{e}^{-(\alpha \mathrm{x})^{\beta}}\right]^{\theta(\mathrm{a}-1)} \\
\times \underbrace{\left\{1-\mathrm{L}\left[1-\mathrm{e}^{-(\alpha \mathrm{x})^{\beta}}\right]^{\mathrm{b}}\right\}^{\theta}}_{A},
\end{gathered}
$$

where $L=\lambda(a+b) /[a(1+\lambda)]$.

Given that $L<1$ and applying a series expansion to $A$, equation (12) can be expressed as

$$
\begin{aligned}
f(x)^{\theta}=\left[a \beta \alpha^{\beta}(1+\lambda)\right]^{\theta} x^{\theta(\beta-1)} e^{-\theta(\alpha x)}{ }^{\beta} & \\
& \times \sum_{j=0}^{\infty}\left(\begin{array}{l}
\theta \\
j
\end{array}\right)(-L)^{j}\left[1-e^{-(\alpha x)^{\beta}}\right]^{b j+\theta(a-1)} .
\end{aligned}
$$

Applying the series expansion to the last equation, we can write

$$
f(x)^{\theta}=\left[a \beta \alpha^{\beta}(1+\lambda)\right]^{\theta} \sum_{j, k=0}^{\infty} m_{j, k} x^{\theta(\beta-1)} e^{-(k+\theta)(\alpha x)^{\beta}},
$$

where $m_{j, k}=\left(\begin{array}{l}\theta \\ j\end{array}\right)\left(\begin{array}{l}b j+\theta(a-1) \\ k\end{array}\right)(-1)^{k+j} L^{j}$.

Then, the Rényi entropy of $X$ is given by

$$
\mathrm{I}_{\theta}(\mathrm{X})=\frac{1}{1-\theta} \log \left\{\sum_{\mathrm{j}, \mathrm{k}=0}^{\infty} \mathrm{m}_{\mathrm{j}, \mathrm{k}} \frac{[\mathrm{a}(1+\lambda)]^{\theta} \beta^{\theta-1}}{\alpha^{\theta+1}(\mathrm{k}+\theta)^{\frac{\theta \beta-\theta+1}{\beta}}} \Gamma\left(\frac{\theta \beta-\theta+1}{\beta}\right)\right\} .
$$

The q-entropy, say $H_{q}(X)$, is defined by

$$
\mathrm{H}_{\mathrm{q}}(\mathrm{X})=\frac{1}{\mathrm{q}-1} \log \left\{1-\int_{-\infty}^{\infty} \mathrm{f}(\mathrm{x})^{\mathrm{q}} \mathrm{dx}\right\}, \mathrm{q}>0 \text { and } \mathrm{q} \neq 1 \text {. }
$$

Hence

$$
\mathrm{H}_{\mathrm{q}}(\mathrm{X})=\frac{1}{\mathrm{q}-1} \log \left\{1-\sum_{\mathrm{j}, \mathrm{k}=0}^{\infty} \mathrm{m}_{\mathrm{j}, \mathrm{k}} \frac{[\mathrm{a}(1+\lambda)]^{\mathrm{q}} \beta^{\mathrm{q}-1}}{\alpha^{\mathrm{q}+1}(\mathrm{k}+\theta)^{\frac{\mathrm{q} \beta-\mathrm{q}+1}{\beta}}} \Gamma\left(\frac{\beta \mathrm{q}-\mathrm{q}+1}{\beta}\right)\right\} .
$$

\subsection{Order statistics}

Let $X_{1}, \ldots, X_{n}$ denote $n$ independent and identically distributed GT-W random variables. Further, let $X_{(1)}, \ldots, X_{(n)}$ denote the order statistics from these $n$ variables. Then, the pdf of the $i$ th order statistic $X_{(i)}$, say $f_{i}(x)$, is given by

$$
\begin{aligned}
& f_{i}(x)=\frac{f(x)}{B(i, n-i+1)} \sum_{j=0}^{n-i}(-1)^{j}\left(\begin{array}{c}
n-i \\
j
\end{array}\right) F(x)^{i+j-1} . \\
& f_{i}(x)=\sum_{j=0}^{n-i} \sum_{k=0}^{\infty}\left\{w_{k, j} h_{b k+a(i+j)}(x)-w_{k, j}^{*} h_{b(k+1)+a(i+j)}(x)\right\},
\end{aligned}
$$


where

and

$$
w_{k, j}=\frac{(-1)^{k+j} a \Gamma(j+i)(1+\lambda)^{j+i-k} \lambda^{k}}{k ! \Gamma(j+i-k)[b k+a(j+i)] B(i, n-i+1)}\left(\begin{array}{c}
n-i \\
j
\end{array}\right)
$$

$$
w_{k, j}^{*}=\frac{w_{k, j} L[b k+a(j+i)]}{[b(k+1)+a(j+i)]} .
$$

and $h_{\delta}$ denotes the EW density function with power parameter $\delta$. Thus, the density function of the GT-W order statistics is a mixture of EW densities. Based on equation (13), we can obtain some structural properties of $X_{i: n}$ from those EW properties.

The $n$th moment of $X_{i: n}$ (for $n>-\beta$ ) is given by

$$
E\left(X_{i: n}^{n}\right)=\sum_{j=0}^{n-i} \sum_{k=0}^{\infty}\left\{w_{k, j} E\left(Y_{b k+a(i+j)}^{n}\right)-w_{k, j}^{*} E\left(Y_{b(k+1)+a(i+j)}^{n}\right)\right\}
$$

Equation (14) reveals that The $n$th moment of $X_{i: n}$ can be expressed as an infinite linear combination of EW moments.

\subsection{Probability weighted moments}

The PWMs are expectations of certain functions of a random variable. They can be derived for any random variable whose ordinary moments exist. The PWM approach can be used for estimating parameters of any distribution whose inverse form cannot be expressed explicitly.

The $(s, r)$ th PWM of $X$, say $\rho_{s, r}$, is defined by

$$
\rho_{\mathrm{s}, \mathrm{r}}=\mathrm{E}\left\{\mathrm{X}^{\mathrm{s}} \mathrm{F}(\mathrm{X})^{\mathrm{r}}\right\}=\int_{-\infty}^{\infty} \mathrm{X}^{\mathrm{s}} \mathrm{F}(\mathrm{x})^{\mathrm{r}} \mathrm{f}(\mathrm{x}) \mathrm{dx} \text {. }
$$

Using equations (4) and (5), we can write

Where

$$
f(x) F(x)^{r}=\sum_{k=0}^{\infty} m_{k} h_{b k+a(r+1)}(x)\left\{1-L G(x)^{b}\right\},
$$

$$
\mathrm{m}_{\mathrm{k}}=(-1)^{\mathrm{k}} \mathrm{a} \Gamma(\mathrm{r}+1) \lambda^{\mathrm{k}}(1+\lambda)^{\mathrm{r}-\mathrm{k}+1} / \mathrm{k} ! \Gamma(\mathrm{r}-\mathrm{k}+1)[\mathrm{bk}+\mathrm{a}[(\mathrm{r}+1)] .
$$

Then, the $(s, r)$ th PWM of $X$ can be expressed as

$$
\rho_{\mathrm{s}, \mathrm{r}}=\sum_{\mathrm{k}=0}^{\infty} \mathrm{m}_{\mathrm{k}} \int_{0}^{\infty} \mathrm{x}^{\mathrm{s}} \mathrm{h}_{\mathrm{bk}+\mathrm{a}(\mathrm{r}+1)}(\mathrm{x})\left\{1-\mathrm{L} \mathrm{G}(\mathrm{x})^{\mathrm{b}}\right\} \mathrm{dx} \text {. }
$$

Therefore, $\rho_{s, r}$ can be defined, as an infinite linear combination of EW moments, by

$$
\rho_{\mathrm{s}, \mathrm{r}}=\sum_{\mathrm{k}=0}^{\infty}\left\{\mathrm{m}_{\mathrm{k}} \mathrm{E}\left(\mathrm{Y}_{\mathrm{bk}+\mathrm{a}(\mathrm{r}+1)}\right)-\mathrm{m}_{\mathrm{k}}^{*} \mathrm{E}\left(\mathrm{Y}_{\mathrm{b}(\mathrm{k}+1)+\mathrm{a}(\mathrm{r}+1)}\right)\right\}
$$

where $m_{k}^{*}=L m_{k}[b k+a[(r+1)] /[b(k+1)+a(r+1)]$ and

$$
\mathrm{E}\left(\mathrm{Y}_{\delta}\right)=\int_{0}^{\infty} \mathrm{x}^{\mathrm{s}} \mathrm{h}_{\delta}(\mathrm{x}) \mathrm{dx} \text {. Therefore, for } \mathrm{n}>-\beta \text {, we obtain }
$$




$$
\begin{aligned}
\rho_{\mathrm{s}, \mathrm{r}} & =\sum_{\mathrm{k}, \mathrm{j}=0}^{\infty}\left(\mathrm{m}_{\mathrm{k}, \mathrm{j}}-\mathrm{m}_{\mathrm{k}, \mathrm{j}}^{*}\right) \alpha^{-\mathrm{s}} \Gamma\left(1+\frac{\mathrm{s}}{\beta}\right) \\
& =\sum_{\mathrm{k}, \mathrm{j}=0}^{\infty} \frac{\mathrm{m}_{\mathrm{k}, \mathrm{j}}}{\alpha^{\mathrm{s}}}\left(1-\frac{\lambda(\mathrm{a}+\mathrm{b})}{\mathrm{a}(1+\lambda)}\right) \Gamma\left(1+\frac{\mathrm{s}}{\beta}\right),
\end{aligned}
$$

where $\mathrm{m}_{\mathrm{k}, \mathrm{j}}^{*}=\mathrm{Lm}_{\mathrm{k}, \mathrm{j}}$ and

$$
\mathrm{m}_{\mathrm{k}, \mathrm{j}}=\frac{(-1)^{\mathrm{k}+\mathrm{j}} \mathrm{a} \Gamma(\mathrm{r}+1) \Gamma[\mathrm{bk}+\mathrm{a}(\mathrm{r}+1)] \lambda^{\mathrm{k}}(1+\lambda)^{\mathrm{r}-\mathrm{k}+1}}{\mathrm{k} ! \mathrm{j} ! \Gamma(\mathrm{r}+1-\mathrm{k}) \Gamma[\mathrm{bk}+\mathrm{a}(\mathrm{r}+1)-\mathrm{j}](\mathrm{j}+1)^{(\mathrm{s}+\beta) / \beta}}
$$

\subsection{Characterization based on two truncated moments}

Here, we provide characterizations of the GT-W distribution in terms of two truncated moments. This characterization result is based on a theorem (see Theorem 1 below) due to Glänzel (1987). The proof of Theorem 1 is given in Glänzel (1990). This result holds also when the interval $H$ is not closed. Moreover, as mentioned above, it could be also applied when the cdf $F$ does not have a closed form. Glänzel (1990) proved that this characterization is stable in the sense of weak convergence.

Theorem 1. Let $(\Omega,, p)$ be a given probability space and let $H=[a, b]$ be an interval for some $a<b(a=-\infty, b=\infty$ mightaswellbeallowed). Let $H: \Omega \rightarrow H$ be acontinuous random variable with cdf $F$ and let $g$ and $h$ be two real functions defined on $H$ such that

$$
\mathrm{E}(\mathrm{g}(\mathrm{x}) \mid \mathrm{X} \geq \mathrm{x})=\mathrm{E}(\mathrm{h}(\mathrm{x}) \mid \mathrm{X} \geq \mathrm{x}) \eta(\mathrm{x}), \mathrm{x} \in \mathrm{H},
$$

is defined with a real function $h$. Assume that $g, h \in C^{1}(H), \eta \in C^{2}(H)$ and $F$ is twice continuously differentiable and strictly monotone function on the set $H$. Finally, assume that the equation $h \eta=g$ has no real solution in the interior of $H$. Then $F$ is uniquely determined by the functions $g, h$ and $\eta$, particularly

$$
F(x)=\int_{a}^{x} c\left|\frac{\eta^{\prime}(u)}{\eta(u) h(u)-g(u)}\right| \exp (-s(u)) d u,
$$

where the function $s$ is a solution of the differential equation $s^{\prime}=\eta^{\prime} h /(\eta h-g)$ and $C$ is the normalization constant, such that ${ }_{H} d F=1$.

\section{Proposition 1.}

Let $X: \Omega \rightarrow(0, \infty)$ be a continuous random variable and let

and

$$
h(x)=\left\{a(1+\lambda)-\lambda(a+b)\left[1-e^{-(\alpha x)^{\beta}}\right]^{b}\right\}^{-1}
$$

$$
g(x)=h(x)\left[1-e^{-(\alpha x)^{\beta}}\right]^{\alpha}
$$

The random variable $X$ belongs to GT-W distribution (5) if and only if the function $\eta$ defined in Theorem 1 has the formand

$$
\eta(x)=\frac{1}{2}\left\{1+\left[1-e^{-(\alpha x)^{\beta}}\right]^{a}\right\} .
$$


Proof.

Let $X$ be a random variable with density (5), then

and

$$
\bar{F}(x) E[h(x) \mid X \geq x]=\frac{1}{a}\left\{1-\left[1-e^{-(\alpha x)^{\beta}}\right]^{a}\right\}
$$

and finally

$$
\overline{\mathrm{F}}(\mathrm{x}) \mathrm{E}[\mathrm{g}(\mathrm{x}) \mid \mathrm{X} \geq \mathrm{x}]=\frac{1}{2 \mathrm{a}}\left\{1-\left[1-\mathrm{e}^{-(\alpha \mathrm{x})^{\beta}}\right]^{2 \mathrm{a}}\right\},
$$

$$
\begin{aligned}
& \eta(x) h(x)-g(x)=\frac{1}{2} h(x)\left[1-e^{-(\alpha x)^{\beta}}\right]^{a}, \\
& S^{\prime}(x)=\frac{\eta^{\prime}(x) h(x)}{\eta(x) h(x)-g(x)}=\frac{a \beta \alpha^{\beta} x^{\beta-1} e^{-(\alpha x)^{\beta}}}{\left[1-e^{-(\alpha x)^{\beta}}\right]} .
\end{aligned}
$$

Then, we have

$$
\mathrm{S}(\mathrm{x})=\operatorname{aln}\left[1-\mathrm{e}^{-(\alpha \mathrm{x})^{\beta}}\right]
$$

Then, $X$ has the pdf (5).

Corollary: Let $X: \Omega \rightarrow(\theta, \infty)$ be a continuous random variable and let $h(x)$ be as in Proposition (1). Then the random variable $X$ has the pdf (5) if and only if the functions $g$ and $h$ defined in Theorem 1 satisfy the following differential equation

$$
\frac{\eta^{\prime}(x) h(x)}{\eta(x) h(x)-g(x)}=\frac{a \beta \alpha^{\beta} x^{\beta-1} e^{-(\alpha x)^{\beta}}}{\left[1-e^{-(\alpha x)^{\beta}}\right]} \text {. }
$$

The general solution of the above differential equation is

$$
\eta(x)=\left[1-e^{-(\alpha x)^{\beta}}\right]^{a}\left\{-\int \frac{a \beta \alpha^{\beta} x^{\beta-1} e^{-(\alpha x)^{\beta}}}{\left[1-e^{-(\alpha x)^{\beta}}\right]} \times \frac{g(x)}{h(x)} d x+K\right\},
$$

where $K$ is a constant. There is a set of functions satisfying the differential equation (15) is given in Proposition 1 with $K=0$. Moreover, there are other triplets $(h, g, \eta)$ satisfying the conditions of Theorem 1.

\section{Estimation}

The maximum likelihood method is the most commonly employed method for parameter estimation among several approaches in the literature. The maximum likelihood estimators (MLEs) have desirable properties and can be used when constructing confidence intervals and regions and also in test statistics. The normal approximation for MLEs in large sample distribution theory is easily handled either analytically or numerically. Therefore, we consider the maximum likelihood to estimate the unknown parameters of the GT-W model from complete samples only. Let $X_{1}, \ldots, X_{n}$ be a random sample of this distribution with unknown parameter vector $v=(\alpha, \beta, \lambda, a, b)^{\mathrm{T}}$. The log-likelihood function for $v$, say $\ell=\ell(v)$, is given by

$$
\begin{gathered}
\ell=n \ln \beta+\mathrm{n} \beta \ln \alpha+(\beta-1) \sum_{\mathrm{i}=1}^{\mathrm{n}} \ln \left(\mathrm{x}_{\mathrm{i}}\right)-\sum_{\mathrm{i}=1}^{\mathrm{n}} \mathrm{s}_{\mathrm{i}} \\
+(\mathrm{a}-1) \sum_{\mathrm{i}=1}^{\mathrm{n}} \ln \left(\mathrm{z}_{\mathrm{i}}\right)+\sum_{\mathrm{i}=1}^{\mathrm{n}} \ln \left(\mathrm{k}_{\mathrm{i}}\right),
\end{gathered}
$$

where $s_{i}=\left(\alpha x_{i}\right)^{\beta}, z_{i}=1-e^{-s_{i}}$ and $k_{i}=\left\{a(1+\lambda)-\lambda(a+b) z_{i}\right\}$. 
Equation (16) can be maximized either directly by using the SAS (PROC NLMIXED), R (optim function) or by solving the nonlinear system of equations obtained by differentiating (16). The score vector is given by $\mathbf{U}(v)=\frac{\partial \ell}{\partial v}=\left(\frac{\partial}{\partial \alpha}, \frac{\partial}{\partial \beta}, \frac{\partial}{\partial \lambda}, \frac{\partial}{\partial a}, \frac{\partial}{\partial b}\right)^{\mathrm{T}}=$ $\left(J_{\alpha}, J_{\beta}, J_{\lambda}, J_{a}, J_{b}\right)^{\mathrm{T}}$. Then,

$$
\begin{aligned}
& \mathrm{J}_{\alpha}=\frac{\mathrm{n} \beta}{\alpha}-\frac{\beta}{\alpha} \sum_{\mathrm{i}=1}^{\mathrm{n}} \mathrm{s}_{\mathrm{i}}-\frac{(\mathrm{a}-1) \beta}{\alpha} \sum_{\mathrm{i}=1}^{\mathrm{n}} \frac{\mathrm{s}_{\mathrm{i}} \mathrm{e}^{-\mathrm{s}_{\mathrm{i}}}}{\mathrm{z}_{\mathrm{i}}}+\frac{\lambda \mathrm{b}(\mathrm{a}+\mathrm{b}) \beta}{\alpha} \sum_{\mathrm{i}=1}^{\mathrm{n}} \frac{\mathrm{s}_{\mathrm{i}} \mathrm{e}^{-\mathrm{s}_{\mathrm{i}}} \mathrm{z}_{\mathrm{i}}}{\mathrm{k}_{\mathrm{i}}}, \\
& \mathrm{J}_{\beta}=\frac{\mathrm{n}}{\beta}+\mathrm{nln} \alpha+_{\mathrm{i}=1}^{\mathrm{n}} \ln \left(\mathrm{x}_{\mathrm{i}}\right)-\sum_{\mathrm{i}=1}^{\mathrm{n}} \mathrm{s}_{\mathrm{i}} \ln \left(\alpha \mathrm{x}_{\mathrm{i}}\right) \\
& \quad+(\mathrm{a}-1) \sum_{\mathrm{i}=1}^{\mathrm{n}} \frac{\mathrm{s}_{\mathrm{i}} \mathrm{e}^{-\mathrm{s}_{\mathrm{i}}}}{\mathrm{z}_{\mathrm{i}}\left[\ln \left(\alpha \mathrm{x}_{\mathrm{i}}\right)\right]^{-1}}+\lambda \mathrm{b}(\mathrm{a}+\mathrm{b}) \sum_{\mathrm{i}=1}^{\mathrm{n}} \frac{\mathrm{s}_{\mathrm{i}} \mathrm{z}_{\mathrm{i}} \mathrm{e}^{-\mathrm{s}_{\mathrm{i}}}}{\mathrm{k}_{\mathrm{i}}\left[\ln \left(\alpha \mathrm{x}_{\mathrm{i}}\right)\right]^{-1}} \\
& \mathrm{~J}_{\lambda}=\sum_{\mathrm{i}=1}^{\mathrm{n}} \frac{\mathrm{a}-(\mathrm{a}+\mathrm{b}) \mathrm{z}_{\mathrm{i}}}{\mathrm{k}_{\mathrm{i}}}, \mathrm{J}_{\mathrm{a}}=\sum_{\mathrm{i}=1}^{\mathrm{n}} \ln \mathrm{z}_{\mathrm{i}}+\sum_{\mathrm{i}=1}^{\mathrm{n}} \frac{1+\lambda-\lambda \mathrm{z}_{\mathrm{i}}^{\mathrm{b}}}{\mathrm{k}_{\mathrm{i}}}
\end{aligned}
$$

and

$$
\mathrm{J}_{\mathrm{b}}=\sum_{\mathrm{i}=1}^{\mathrm{n}} \frac{\lambda \mathrm{z}_{\mathrm{i}}^{\mathrm{b}}+\lambda^{2} \mathrm{z}_{\mathrm{i}} \ln \mathrm{z}_{\mathrm{i}}}{\mathrm{k}_{\mathrm{i}}}
$$

We can obtain the estimates of the unknown parameters by setting the score vector to zero, $\mathbf{U}(\hat{v})=0$. By solving these equations simultaneously gives the MLEs $\hat{\alpha}, \hat{\beta}, \hat{\lambda}, \hat{a}$ and $\hat{b}$. Statistical software can be used to solve these equations numerically by means of iterative techniques such as the Newton-Raphson algorithm because they can not be solved analytically. For the GT-W distribution all the second order derivatives exist.

For interval estimation of the model parameters, we require the $5 \times 5$ observed information matrix $J(v)=\left\{J_{r s}\right\}$ for $r, s=\alpha, \beta, \lambda, a, b$, whose elements are given in the Appendix. Under standard regularity conditions, the multivariate normal $N_{5}\left(0, J(\widehat{v})^{-1}\right)$ distribution can be used to construct approximate confidence intervals for the model parameters. Here, $J(\hat{v})$ is the total observed information matrix evaluated at $\hat{v}$. Therefore, approximate $100(1-\phi) \%$ confidence intervals for $\alpha, \beta, \lambda, a$ and $b$ can be determined as:

$\widehat{\alpha} \pm z_{\phi / 2} \sqrt{\hat{J}_{\alpha \alpha}}, \hat{\beta} \pm z_{\phi / 2} \sqrt{\hat{J}_{\beta \beta}}, \hat{\lambda} \pm z_{\phi / 2} \sqrt{\hat{\mathrm{J}}_{\mathrm{aa}}}, \quad \hat{\mathrm{a}} \pm \mathrm{z}_{\phi / 2} \sqrt{\hat{\mathrm{J}}_{\mathrm{aa}}}$ and $\hat{\mathrm{b}} \pm z_{\phi / 2} \sqrt{\hat{J}_{b b}}$, where $z_{\phi / 2}$ is the upper $\phi$ th percentile of the standard normal distribution.

\section{Simulation Study}

In this section, we conduct a small Monte Carlo simulation based on 3000 Monte Carlo replications. The true parameter values used in the data generating processes are $a=0.1$, $b=0.5, \alpha=1, \beta=7.3$ and $\lambda=-0.8$. Different sample sizes $n=50,60,70,80,90$, 100, 150, 200 and 500 were considered. The mean estimate, bias and the root-meansquare error (RMSE) of the parameter estimates for the maximum likelihood estimates were determined from this simulation study and are presented in Table 2. It can be seen 
that the estimates are stable and quite close the true parameter values for these sample sizes. Furthermore, as the sample size increases the RMSE decreases in all cases.

Table 3: Mean estimates, bias and root mean squared errors of $a, b, \alpha, \beta$ and $\lambda$

\begin{tabular}{|c|c|c|c|c|}
\hline$n$ & Parameter & Mean estimate & Bias & RMSE \\
\hline \multirow{5}{*}{$\begin{array}{l}\circ \\
\text { 노 } \\
\text { II } \\
\approx\end{array}$} & $a=0.1$ & 0.2297822 & -0.1297822 & 0.327024463 \\
\hline & $b=0.5$ & 1.255719 & -0.755719 & 8.109112849 \\
\hline & $\alpha=1$ & 1.541074 & -0.541074 & 0.955562124 \\
\hline & $\beta=7.3$ & 6.748934 & 0.551066 & 2.947305334 \\
\hline & $\lambda=-0.8$ & -0.5511439 & -0.2488561 & 0.5905149096 \\
\hline \multirow{5}{*}{$\begin{array}{l}8 \\
\| \\
\approx\end{array}$} & $a=0.1$ & 0.1951376 & -0.0951376 & 0.220395469 \\
\hline & $b=0.5$ & 1.032509 & -0.532509 & 5.96435795 \\
\hline & $\alpha=1$ & 1.4754 & -0.4754 & 0.72339841 \\
\hline & $\beta=7.3$ & 6.84503 & 0.45497 & 2.78995353 \\
\hline & $\lambda=-0.8$ & -0.6011422 & -0.1988578 & 0.523234483 \\
\hline \multirow{5}{*}{$\begin{array}{l}\stackrel{2}{R} \\
\text { II } \\
\approx\end{array}$} & $a=0.1$ & 0.1912887 & -0.0912887 & 0.212256016 \\
\hline & $b=0.5$ & 0.9122504 & -0.4122504 & 5.016811775 \\
\hline & $\alpha=1$ & 1.471143 & -0.471143 & 0.691495355 \\
\hline & $\beta=7.3$ & 6.803299 & 0.496701 & 2.7090957685 \\
\hline & $\lambda=-0.8$ & -0.6263422 & -0.1736578 & 0.4825763478 \\
\hline \multirow{5}{*}{$\begin{array}{l}\infty \\
\| \\
\approx \\
\approx\end{array}$} & $a=0.1$ & 0.1624461 & -0.0624461 & 0.1819903167 \\
\hline & $b=0.5$ & 0.8991859 & -0.3991859 & 4.4955866560 \\
\hline & $\alpha=1$ & 1.428468 & -0.428468 & 0.5563865805 \\
\hline & $\beta=7.3$ & 6.975834 & 0.324166 & 2.44068711545 \\
\hline & $\lambda=-0.8$ & -0.6818705 & -0.1181295 & 0.4220811281 \\
\hline \multirow{5}{*}{$\begin{array}{l}8 \\
\text { व } \\
\approx\end{array}$} & $a=0.1$ & 0.1525878 & -0.0525878 & 0.1627860458 \\
\hline & $b=0.5$ & 0.7091427 & -0.2091427 & 3.1018647083 \\
\hline & $\alpha=1$ & 1.411616 & -0.411616 & 0.5011926789 \\
\hline & $\beta=7.3$ & 7.074512 & 0.225488 & 2.3617131151 \\
\hline & $\lambda=-0.8$ & -0.712956 & -0.087044 & 0.4007942838 \\
\hline \multirow{5}{*}{$\begin{array}{l}\stackrel{8}{\circ} \\
\stackrel{-}{1} \\
\text { II } \\
\approx\end{array}$} & $a=0.1$ & 0.1449813 & -0.0449813 & 0.1496813193 \\
\hline & $b=0.5$ & 0.6207838 & -0.1207838 & 2.5477297200 \\
\hline & $\alpha=1$ & 1.397203 & -0.397203 & 0.4871008552 \\
\hline & $\beta=7.3$ & 7.145722 & 0.154278 & 2.2156427287 \\
\hline & $\lambda=-0.8$ & -0.7271562 & -0.0728438 & 0.3935592956 \\
\hline
\end{tabular}


Table 3: Mean estimates, bias and root mean squared errors of $a, b, \alpha, \beta$ and $\lambda$ (Continuing)

\begin{tabular}{|c|c|c|c|c|}
\hline$n$ & Parameter & Mean estimate & Bias & RMSE \\
\hline \multirow{5}{*}{$\begin{array}{l}0 \\
\text { 노 } \\
\text { - } \\
11 \\
2\end{array}$} & $a=0.1$ & 0.1396533 & -0.0396533 & 0.1166192274 \\
\hline & $b=0.5$ & 0.58137 & -0.08137 & 1.2698756147 \\
\hline & $\alpha=1$ & 1.355434 & -0.355434 & 0.3992931734 \\
\hline & $\beta=7.3$ & 7.200587 & 0.099413 & 1.7022385098 \\
\hline & $\lambda=-0.8$ & -0.7353586 & -0.0646414 & 0.3502029562 \\
\hline \multirow{5}{*}{$\begin{array}{l}\stackrel{\bigcirc}{\circ} \\
\text { N } \\
\text { II } \\
\text { \& }\end{array}$} & $a=0.1$ & 0.12117204 & -0.02117204 & 0.0940367283 \\
\hline & $b=0.5$ & 0.5507085 & -0.0507085 & 0.826900932 \\
\hline & $\alpha=1$ & 1.333046 & -0.333046 & 0.3186760245 \\
\hline & $\beta=7.3$ & 7.234297 & 0.065703 & 1.4922472233 \\
\hline & $\lambda=-0.8$ & -0.7638331 & -0.0361669 & 0.3033842689 \\
\hline \multirow{5}{*}{$\begin{array}{c}8 \\
0 \\
\text { ㅇ } \\
\text { II } \\
\approx\end{array}$} & $a=0.1$ & 0.10117204 & -0.00117204 & 0.051629824 \\
\hline & $b=0.5$ & 0.5007085 & -0.0007085 & 0.698312924 \\
\hline & $\alpha=1$ & 1.211367 & -0.211367 & 0.2242738698 \\
\hline & $\beta=7.3$ & 7.2912457 & 0.0087543 & 0.7600244960 \\
\hline & $\lambda=-0.8$ & -0.7936831 & -0.0063169 & 0.2012870279 \\
\hline
\end{tabular}

\section{Application}

In this section, we provide an application of the GT-W distribution to show the importance of the new model. We now provide a data analysis in order to assess the goodness-of-fit of the proposed model. We will make the use of the data set on the remission times (in months) of a random sample of 128 bladder cancer patients (Lee and Wang, 2003) is given by: 0.08, 2.09, 3.48, 4.87, 6.94, 8.66, 13.11, 23.63, 0.20, 2.23, 3.52, $4.98,6.97,9.02,13.29,0.40,2.26,3.57,5.06,7.09,9.22,13.80,25.74,0.50,2.46,3.64$, $5.09,7.26,9.47,14.24,25.82,0.51,2.54,3.70,5.17,7.28,9.74,14.76,26.31,0.81,2.62$, $3.82,5.32,7.32,10.06,14.77,32.15,2.64,3.88,5.32,7.39,10.34,14.83,34.26,0.90$, $2.69,4.18,5.34,7.59,10.66,15.96,36.66,1.05,2.69,4.23,5.41,7.62,10.75,16.62$, $43.01,1.19,2.75,4.26,5.41,7.63,17.12,46.12,1.26,2.83,4.33,5.49,7.66,11.25,17.14$, $79.05,1.35,2.87,5.62,7.87,11.64,17.36,1.40,3.02,4.34,5.71,7.93,11.79,18.10,1.46$, $4.40,5.85,8.26,11.98,19.13,1.76,3.25,4.50,6.25,8.37,12.02,2.02,3.31,4.51,6.54$, $8.53,12.03,20.28,2.02,3.36,6.76,12.07,21.73,2.07,3.36,6.93,8.65,12.63,22.69$. These data were previously studied by Mead and Afify (2017) to fit the Kumaraswamy exponentiated Burr XII distribution. We compare the fits of the GT-W distribution with other competitive models, namely: the McDonald Weibull (McW) (Cordeiro et al., 2014), transmuted linear exponential (TLE) (Tian et al., 2014), transmuted modified Weibull (TMW) (Khan and King, 2013), modified beta Weibull (MBW) (Khan, 2015), transmuted additive Weibull distribution (TAW) (Elbatal and Aryal, 2013), exponentiated transmuted generalized Rayleigh (ETGR) (Afify et al., 2015) and Weibull (W) distributions with corresponding densities (for $x>0$ ):

- $\mathrm{McW}: f(x)=\frac{\beta c \alpha^{\beta}}{B(a / c, b)} x^{\beta-1} e^{-(\alpha x)^{\beta}}\left[1-e^{-(\alpha x)^{\beta}}\right]^{a-1}\left\{1-\left(1-e^{-(\alpha x)^{\beta}}\right)^{c}\right\}^{b-1}$. 
- TLE: $f(x)=(\alpha+\gamma x)\left[1-e^{-\left(\alpha x+\frac{\gamma}{2} x^{2}\right)}\right]\left\{1-\lambda+2 \lambda e^{-\left(\alpha x+\frac{\gamma}{2} x^{2}\right)}\right\}$.

- TMW: $f(x)=\left(\alpha+\gamma \beta x^{\beta-1}\right) e^{-\left(\alpha x+\gamma x^{\beta}\right)}\left\{1-\lambda+2 \lambda e^{-\left(\alpha x+\gamma x^{\beta}\right)}\right\}$.

- MBW: $f(x)=\frac{\beta \alpha^{-\beta} c^{a}}{B(a / c, b)} x^{\beta-1} e^{-b\left(\frac{x}{\alpha}\right)^{\beta}}\left[1-e^{-\left(\frac{x}{\alpha}\right)^{\beta}}\right]^{a-1}$

$$
\times\left\{1-(1-c)\left(1-e^{-\left(\frac{x}{\alpha}\right)^{\beta}}\right)^{c}\right\}^{-a-b}
$$

- TAW: $f(x)=\left(\alpha \theta x^{\theta-1}+\gamma \beta x^{\beta-1}\right) e^{-\left(\alpha x^{\theta}+\gamma x^{\beta}\right)}\left\{1-\lambda+2 \lambda e^{-\left(\alpha x^{\theta}+\gamma x^{\beta}\right)}\right\}$.

- ETGR: $f(x)=2 \alpha \gamma \beta^{2} x e^{-(\beta x)^{2}}\left[1-e^{-(\beta x)^{2}}\right]^{\alpha \gamma-1}$

$$
\times\left[1+\lambda-2 \lambda\left(1-e^{-(\beta x)^{2}}\right)^{\alpha}\right]\left\{1+\lambda-\lambda\left(1-e^{-(\beta x)^{2}}\right)^{\alpha}\right\}^{\gamma-1} \text {. }
$$

The parameters of the above densities are all positive real numbers except for the TLE, TMW, TAW and ETGR distributions for which $|\lambda| \leq 1$ and $0<\theta<\beta$ (or $0<\beta<\theta$ ) for the TAW.

In order to compare the fitted models, we consider some goodness-of-fit measures including the Akaike information criterion $(A I C)$, consistent Akaike information criterion $(C A I C)$ and $-2 \hat{\ell}$, where $\hat{\ell}$ is the maximized log-likelihood, $A I C=-2 \hat{\ell}+2 p, C A I C=$ $-2 \hat{\ell}+2 p n /(n-p-1), p$ is the number of parameters and $n$ is the sample size. Moreover, we use the Anderson-Darling $\left(A^{*}\right)$ and the Cramér-von Mises $\left(W^{*}\right)$ statistics in order to compare the fits of the two new models with other nested and non-nested models. The statistics are widely used to determine how closely a specific cdf fits the empirical distribution of a given data set. These statistics are given by

and

$$
A^{*}=\left(\frac{9}{4 n^{2}}+\frac{3}{4 n}+1\right)\left\{n+\frac{1}{n} \sum_{j=1}^{n}(2 j-1) \log \left[z_{i}\left(1-z_{n-j+1}\right)\right]\right\}
$$

$$
W^{*}=\left(\frac{1}{2 n}+1\right)\left\{\sum_{j=1}^{n}\left(z_{i}-\frac{2 j-1}{2 n}\right)^{2}+\frac{1}{12 n}\right\},
$$

respectively, $z_{i}=F\left(y_{j}\right)$, where the $y_{j}$ 's values are the ordered observations. The smaller these statistics are, the better the fit. Upper tail percentiles of the asymptotic distributions of these goodness-of-fit statistics were tabulated in Nichols and Padgett (2006).

Table 4 lists the values of $-2 \hat{\ell}, A I C, C A I C, W^{*}$ and $A^{*}$ whereas the MLEs, their corresponding standard errors, of the model parameters are given in Table 5. These numerical results are obtained using the MATH-CAD PROGRAM.

The fitted pdf, estimated cdf and QQ-plot of the GT-W model are displayed in Figures 5 and 6 , respectively. 
In Table 4, we compare the fits of the GT-W model with the Mc-W, TLE, TMW, MBW, TAW, ETGR and W models. We note that the GT-W model has the lowest values for the $-2 \widehat{\ell}, A I C, C A I C, W^{*}$ and $A^{*}$ statistics among all fitted models. So, the GT-W model could be chosen as the best model. It is quite clear from the figures in Table 2 and Figures 3 and 4, that the GT-W distribution can provide the best fits to these data. So, we prove that this new model can be better model than other competitive lifetime models.

Table 4: The statistics $-2 \widehat{\ell}, A I C, C A I C, W^{*}$ and $A^{*}$ for cancer patient data

\begin{tabular}{|c|c|c|c|c|c|}
\hline \hline Model & $-2 \hat{\ell}$ & $A I C$ & $C A I C$ & $W^{*}$ & $A^{*}$ \\
\hline GT-W & 821.347 & 831.347 & 831.839 & 0.04691 & 0.30583 \\
\hline McW & 821.68 & 831.68 & 832.172 & 0.05037 & 0.32985 \\
\hline TLE & 826.971 & 832.971 & 833.165 & 0.06085 & 0.55402 \\
\hline W & 828.158 & 832.158 & 832.254 & 0.10553 & 0.66279 \\
\hline TMW & 828.45 & 836.45 & 836.775 & 0.12511 & 0.76028 \\
\hline MBW & 828.027 & 838.027 & 838.519 & 0.10679 & 0.72074 \\
\hline TAW & 828.478 & 838.478 & 838.97 & 0.11288 & 0.70326 \\
\hline ETGR & 858.35 & 866.35 & 866.675 & 0.39794 & 2.36077 \\
\hline \hline
\end{tabular}

Table 5: MLEs and their standard errors for cancer patient data

\begin{tabular}{|c|c|c|c|c|c|}
\hline \hline Model & $\alpha$ & $\beta$ & $a$ & $b$ & $\lambda$ \\
\hline $\mathrm{W}$ & 9.5593 & 1.0477 & 1 & 1 & 0 \\
& $(0.853)$ & $(0.068)$ & - & - & - \\
\hline GT-W & 0.2991 & 0.6542 & 2.7965 & 0.0128 & 0.002 \\
& $(0.151)$ & $(0.121)$ & $(1.117)$ & $(7.214)$ & $(1.769)$ \\
\hline & $\alpha$ & $\beta$ & $a$ & $b$ & $c$ \\
\hline McW & 0.1192 & 0.5582 & 4.0633 & 2.6036 & 0.0393 \\
& $(0.109)$ & $(0.178)$ & $(2.111)$ & $(2.452)$ & $(0.202)$ \\
\hline MBW & 10.1502 & 0.1632 & 57.4167 & 19.3859 & 2.0043 \\
& $(22.437)$ & $(0.044)$ & $(37.317)$ & $(13.49)$ & $(0.789)$ \\
\hline & $\alpha$ & $\beta$ & $\gamma$ & $\theta$ & $\lambda$ \\
\hline TAW & 0.1139 & 0.9722 & $3.0936 \times 10^{-5}$ & 1.0065 & -0.163 \\
& $(0.032)$ & $(0.125)$ & $\left(6.106 \times 10^{-3}\right)$ & $(0.035)$ & $(0.28)$ \\
\hline TLE & $\alpha$ & $\gamma$ & $\lambda$ & & \\
\hline & 0.0612 & $3.0877 \times 10^{-5}$ & 0.8568 & & \\
& $(0.01)$ & $\left(6.819 \times 10^{-4}\right)$ & $(0.203)$ & & \\
\hline & $\alpha$ & $\beta$ & $\gamma$ & $\lambda$ & \\
\hline TMW & 0.1208 & 0.8955 & 0.0002 & -0.2513 & \\
& $(0.024)$ & $(0.626)$ & $(0.011)$ & $(0.407)$ & \\
\hline ETGR & 7.3762 & 0.0473 & 0.0494 & 0.118 & \\
& $(5.389)$ & $\left(3.965 \times 10^{-3}\right)$ & $(0.036)$ & $(0.26))$ & \\
\hline \hline
\end{tabular}



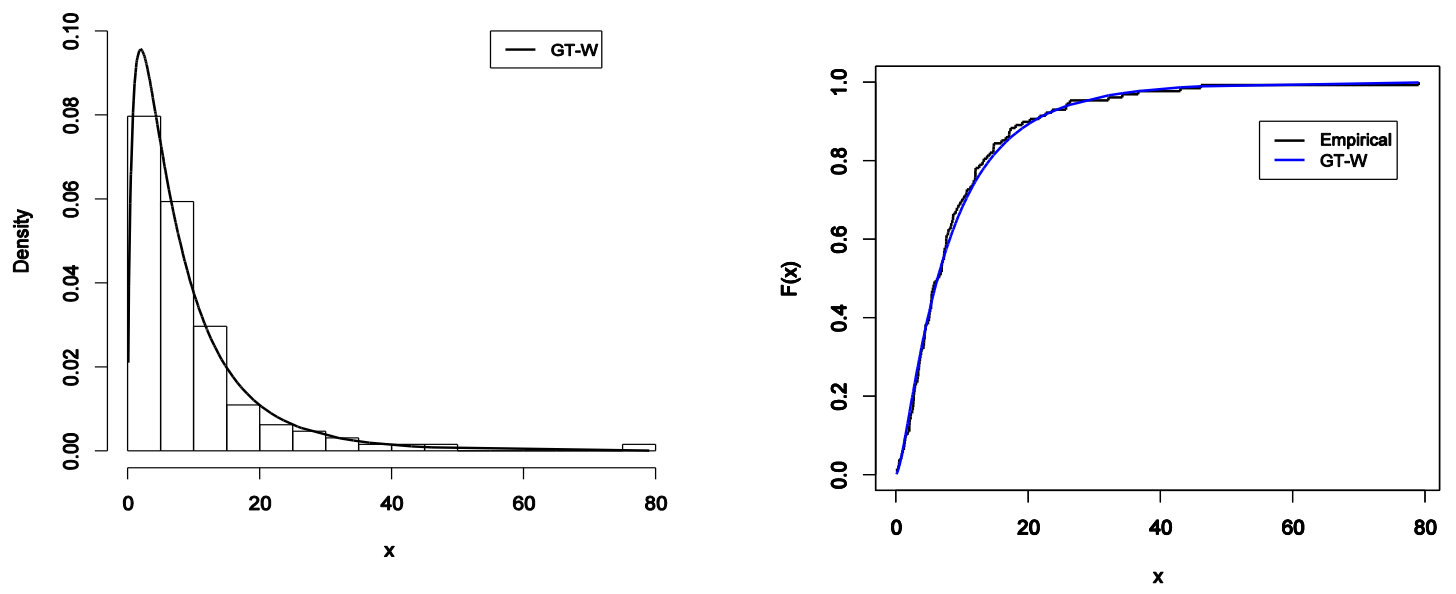

Figure 5: The fitted pdf and estimated cdf of the GT-W model

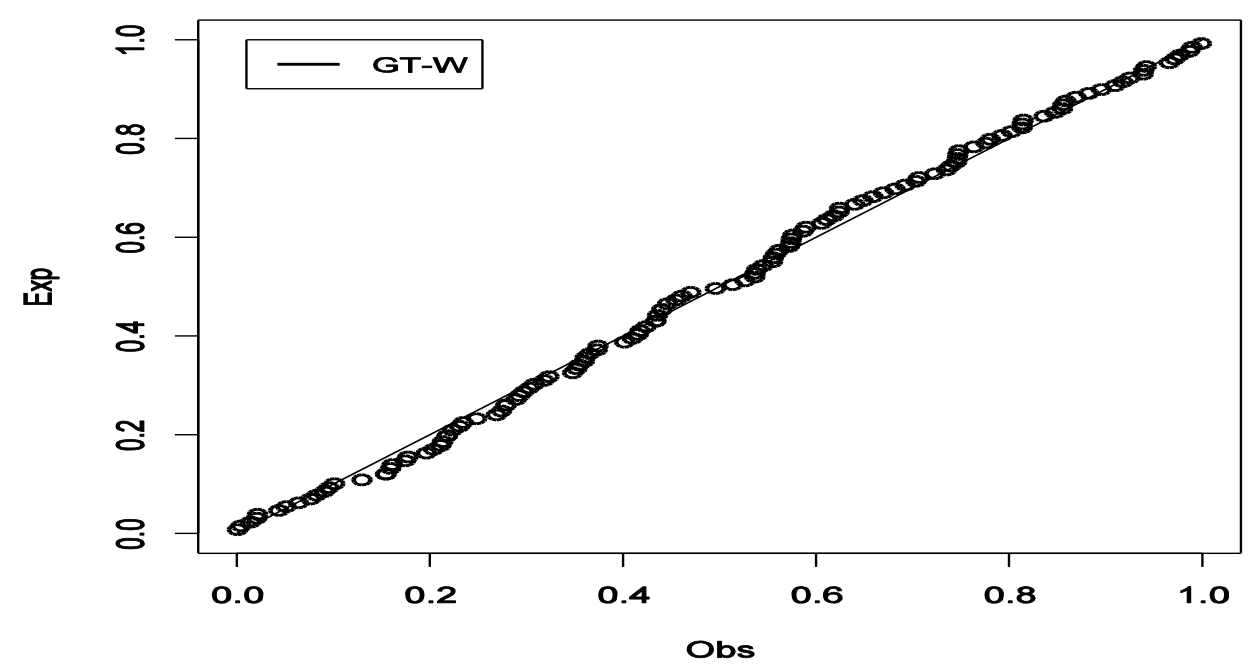

Figure 6: QQ-plot of the GT-W model

\section{Conclusions}

In this paper, we propose and study a new model, based on the GT-G family proposed by Nofal et al. (2017), called the generalized transmuted Weibull (GT-W) model, which extends the Weibull distribution. An obvious reason for generalizing a classical distribution is the fact that the new model provides more flexibility to analyze real life data. We provide some of its mathematical and statistical properties. The GT-W density function can be expressed as a mixture of EW densities. We derive explicit expressions for the ordinary and incomplete moments, quantile and generating functions, probability weighted moments, Rényi and q-entropies and order statistics. We discuss maximum likelihood estimation. The proposed distribution applied to a real data set provides better fits than some other nested non-nested models. We hope that the proposed model will 
attract wider application in areas such as engineering, reliability, survival and lifetime data, hydrology, economics and others.

\section{Appendix}

The elements of the observed information matrix are given by

$$
\begin{aligned}
& J_{\alpha \alpha}=\frac{-n \beta}{\alpha^{2}}+\frac{\beta(1-\beta)}{\alpha^{2}} \sum_{i=1}^{n} s_{i}+\frac{(a-1) \beta}{\alpha^{2}} \sum_{i=1}^{n} \frac{s_{i} e^{-s_{i}}\left[1-\beta\left(1-s_{i}\right)\right]}{z_{i}} \\
& +\frac{\lambda b(a+b) \beta}{\alpha^{2}} \sum_{i=1}^{n} \frac{s_{i} e^{-s_{i}} z_{i}\left[(b-1) s_{i} e^{-s_{i}} k_{i}-\lambda b(a+b) z_{i}\right]}{k_{i}} \\
& -\frac{\lambda b(a+b) \beta}{\alpha^{2}} \sum_{i=1}^{n} \frac{s_{i} e^{-s_{i}} z_{i}\left[1-\beta\left(1-s_{i}\right)\right]}{k_{i}} \\
& \mathrm{~J}_{\alpha \beta}=\frac{\mathrm{n}}{\alpha}-\frac{1}{\alpha} \sum_{\mathrm{i}=1}^{\mathrm{n}} \mathrm{s}_{\mathrm{i}}\left[1+\beta \ln \left(\alpha \mathrm{x}_{\mathrm{i}}\right)\right]\left[1+(\mathrm{a}-1) \frac{\mathrm{e}^{-\mathrm{s}_{\mathrm{i}}}}{\mathrm{z}_{\mathrm{i}}}\right] \\
& -\frac{(\mathrm{a}-1)}{\alpha} \sum_{\mathrm{i}=1}^{\mathrm{n}} \frac{\mathrm{s}_{\mathrm{i}} \mathrm{e}^{-\mathrm{s}_{\mathrm{i}}}\left[\beta \mathrm{s}_{\mathrm{i}} \mathrm{e}^{-\mathrm{s}_{\mathrm{i}}}+\beta \mathrm{s}_{\mathrm{i}} \mathrm{z}_{\mathrm{i}}\right]}{\mathrm{z}_{\mathrm{i}}\left[\ln \left(\alpha \mathrm{x}_{\mathrm{i}}\right)\right]^{-1}} \\
& +\frac{\lambda b(a+b)}{\alpha} \sum_{i=1}^{n} \frac{s_{i} e^{-s_{i}} z_{i}\left[1+\beta\left(1-s_{i}\right)\right]}{k_{i}\left[\ln \left(\alpha x_{i}\right)\right]^{-1}} \\
& -\frac{\lambda b(a+b) \beta}{\alpha} \sum_{i=1}^{n} \frac{s_{i} e^{-2 s_{i}} z_{i}}{k_{i}}\left\{\frac{\lambda b z_{i}^{b}}{(a+b)^{-1}}+\frac{(b-1) k_{i}}{\left[\ln \left(\alpha x_{i}\right)\right]^{-1}}\right\}, \\
& \mathrm{J}_{\alpha \lambda}=\frac{\mathrm{b}(\mathrm{a}+\mathrm{b}) \beta}{\alpha} \sum_{\mathrm{i}=1}^{\mathrm{n}} \frac{\mathrm{s}_{\mathrm{i}} \mathrm{e}^{-\mathrm{s}_{\mathrm{i}}} \mathrm{z}_{\mathrm{i}}}{\mathrm{k}_{\mathrm{i}}}\left\{\mathrm{k}_{\mathrm{i}}-\lambda\left[\mathrm{a}-(\mathrm{a}+\mathrm{b}) \mathrm{z}_{\mathrm{i}}\right]\right\}, \\
& \mathrm{J}_{\alpha \mathrm{a}}=\frac{-\beta}{\alpha} \sum_{\mathrm{i}=1}^{\mathrm{n}} \frac{\mathrm{s}_{\mathrm{i}} \mathrm{e}^{-\mathrm{s}_{\mathrm{i}}}}{\mathrm{z}_{\mathrm{i}}}+\frac{\lambda \mathrm{b} \beta}{\alpha} \sum_{\mathrm{i}=1}^{\mathrm{n}} \frac{\mathrm{s}_{\mathrm{i}} \mathrm{e}^{-\mathrm{s}_{\mathrm{i}}} \mathrm{z}_{\mathrm{i}}\left\{\mathrm{k}_{\mathrm{i}}-(\mathrm{a}+\mathrm{b})\left[1+\lambda-\lambda \mathrm{z}_{\mathrm{i}}^{\mathrm{b}}\right]\right\}}{\mathrm{k}_{\mathrm{i}}} \\
& \mathrm{J}_{\alpha b}=\frac{\lambda^{2} \mathrm{~b}(\mathrm{a}+\mathrm{b}) \beta}{\alpha} \sum_{\mathrm{i}=1}^{\mathrm{n}} \frac{\mathrm{s}_{\mathrm{i}} \mathrm{e}^{-\mathrm{s}_{\mathrm{i}} \mathrm{z}_{\mathrm{i}}\left[1+\lambda \ln \mathrm{z}_{\mathrm{i}}\right]}}{\mathrm{k}_{\mathrm{i}}}
\end{aligned}
$$

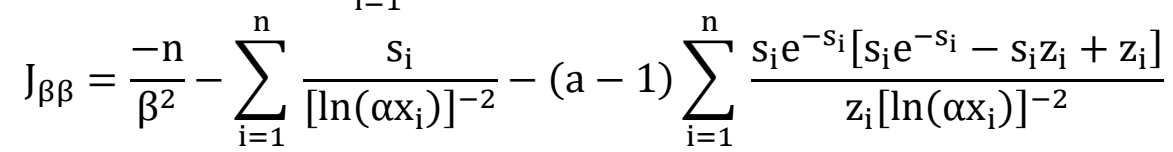

$$
\begin{aligned}
& -\lambda b(a+b) \sum_{i=1}^{n} \frac{s_{i} e^{-s_{i}} z_{i}\left[\ln \left(\alpha x_{i}\right)\right]^{2}\left[k_{i} z_{i}-\lambda b(a+b) z_{i} s_{i} e^{-s_{i}}\right]}{k_{i}} \\
& +\lambda b(a+b) \sum_{i=1}^{n} \frac{s_{i} e^{-s_{i}} z_{i}\left[\ln \left(\alpha x_{i}\right)\right]^{2}\left[s_{i} k_{i} z_{i}+(b-1) k_{i} s_{i} e^{-s_{i}}\right]}{k_{i}}, \\
& \mathrm{~J}_{\beta \lambda}=-\mathrm{b}(\mathrm{a}+\mathrm{b}) \sum_{\mathrm{i}=1}^{\mathrm{n}} \frac{\mathrm{s}_{\mathrm{i}} \mathrm{e}^{-\mathrm{s}_{\mathrm{i}}} \mathrm{z}_{\mathrm{i}}\left\{\mathrm{k}_{\mathrm{i}}-\lambda\left[\mathrm{a}-(\mathrm{a}+\mathrm{b}) \mathrm{z}_{\mathrm{i}}\right]\right\}}{\mathrm{k}_{\mathrm{i}}\left[\ln \left(\alpha \mathrm{x}_{\mathrm{i}}\right)\right]^{-1}}
\end{aligned}
$$




$$
\begin{aligned}
& \mathrm{J}_{\beta \mathrm{a}}=-\sum_{\mathrm{i}=1}^{\mathrm{n}} \frac{\mathrm{s}_{\mathrm{i}} \mathrm{e}^{-\mathrm{s}_{\mathrm{i}}}}{\mathrm{z}_{\mathrm{i}}\left[\ln \left(\alpha \mathrm{x}_{\mathrm{i}}\right)\right]^{-1}}-\lambda \mathrm{b} \sum_{\mathrm{i}=1}^{\mathrm{n}} \frac{\mathrm{s}_{\mathrm{i}} \mathrm{e}^{-\mathrm{s}_{\mathrm{i}}} \mathrm{z}_{\mathrm{i}}\left\{\mathrm{k}_{\mathrm{i}}-(\mathrm{a}+\mathrm{b})\left[1+\lambda-\lambda \mathrm{z}_{\mathrm{i}}^{\mathrm{b}}\right]\right\}}{\mathrm{k}_{\mathrm{i}}\left[\ln \left(\alpha \mathrm{x}_{\mathrm{i}}\right)\right]^{-1}}, \\
& \mathrm{~J}_{\beta \mathrm{b}}=\sum_{\mathrm{i}=1}^{\mathrm{n}} \frac{-\mathrm{s}_{\mathrm{i}} \mathrm{e}^{-\mathrm{s}_{\mathrm{i}}} \mathrm{z}_{\mathrm{i}}\left\{\lambda(\mathrm{a}+2 \mathrm{~b}) \mathrm{k}_{\mathrm{i}}+\lambda^{2} \mathrm{~b}(\mathrm{a}+\mathrm{b}) \mathrm{z}_{\mathrm{i}}\left(1+\lambda \ln \mathrm{z}_{\mathrm{i}}\right)\right\}}{\mathrm{k}_{\mathrm{i}}\left[\ln \left(\alpha \mathrm{x}_{\mathrm{i}}\right)\right]^{-1}} \text {, } \\
& \mathrm{J}_{\lambda \lambda}=-\sum_{\mathrm{i}=1}^{\mathrm{n}}\left\{\frac{\mathrm{a}-(\mathrm{a}+\mathrm{b}) \mathrm{z}_{\mathrm{i}}}{\mathrm{k}_{\mathrm{i}}}\right\}^{2}, \mathrm{~J}_{\lambda \mathrm{a}}=-\sum_{\mathrm{i}=1}^{\mathrm{n}} \frac{\left[1+\lambda-\lambda \mathrm{z}_{\mathrm{i}}^{\mathrm{b}}\right]\left[\mathrm{a}-(\mathrm{a}+\mathrm{b}) \mathrm{z}_{\mathrm{i}}\right]}{\mathrm{k}_{\mathrm{i}}}, \\
& \mathrm{J}_{\lambda \mathrm{b}}=-\sum_{\mathrm{i}=1}^{\mathrm{n}} \frac{\mathrm{z}_{\mathrm{i}}\left[1+\lambda \ln \mathrm{z}_{\mathrm{i}}\right]}{\mathrm{k}_{\mathrm{i}}\left\{\mathrm{k}_{\mathrm{i}}-\lambda\left[\mathrm{a}-(\mathrm{a}+\mathrm{b}) \mathrm{z}_{\mathrm{i}}\right]\right\}^{-1}}, \mathrm{~J}_{\mathrm{aa}}=-\sum_{\mathrm{i}=1}^{\mathrm{n}}\left[\frac{1+\lambda-\lambda \mathrm{z}_{\mathrm{i}}^{\mathrm{b}}}{\mathrm{k}_{\mathrm{i}}}\right]^{2} \text {, } \\
& \mathrm{J}_{\mathrm{ab}}=\lambda \sum_{\mathrm{i}=1}^{\mathrm{n}} \frac{\mathrm{z}_{\mathrm{i}}\left[1+\lambda-\lambda \mathrm{z}_{\mathrm{i}}^{\mathrm{b}}\right]\left[1+\lambda \ln \mathrm{z}_{\mathrm{i}}\right]}{\mathrm{k}_{\mathrm{i}}} \operatorname{and}_{\mathrm{bb}}=-\lambda^{2} \sum_{\mathrm{i}=1}^{\mathrm{n}} \frac{\mathrm{z}_{\mathrm{i}}\left[1+\lambda \ln \mathrm{z}_{\mathrm{i}}\right]^{2}}{\mathrm{k}_{\mathrm{i}}} \text {. }
\end{aligned}
$$

\section{References}

1. Afify, A. Z., Cordeiro, G. M., Butt, N. S., Ortega, E. M. M. and Suzuki, A. K. (2016) A new lifetime model with variable shapes for the hazard rate, Brazilian Journal of Probability and Statistics. Forthcoming.

2. Afify, A. Z., Nofal, Z. M. and Butt, N. S. (2014). Transmuted complementary Weibull geometric distribution. Pakistan Journal of Statistics and Operation Research, 10, 435-454.

3. Afify, A. Z., Nofal, Z. M. and Ebraheim, A. N. (2015). Exponentiated transmuted generalized Rayleigh distribution: a new four parameter Rayleigh distribution, Pakistan Journal of Statistics and Operation Research, 11, 115-134.

4. Afify, A. Z., Yousof, H. M. and Nadarajah, S. (2017). The beta transmuted-H family for lifetime data, Statistics and Its Interface. 10, 505-520.

5. Ahmad, I., Kayid, M., and Pellerey, F. (2005). Further results involving the MIT order and the IMIT class. Probability in the Engineering and Informational Science, 19, 377-395.

6. Alexander, C., Cordeiro, G. M., Ortega, E. M. M. and Sarabia, J. M. (2012). Generalized beta-generated distributions, Computational Statistics and Data Analysis, 56, 1880-1897.

7. Aryal, G. R. and Tsokos, C. P. (2011). Transmuted Weibull distribution: a generalization of the Weibull probability distribution. European Journal of Pure and Applied Mathematics, 4, 89-102.

8. Bourguignon, M., Silva, R. B. and Cordeiro, G. M. (2014). The Weibull-G family of probability distributions, Journal of Data Science, 12, 53-68.

9. Cordeiro, G. M. and de Castro, M. (2011). A new family of generalized distributions, Journal of Statistical Computation and Simulation, 81, 883-893.

10. Cordeiro, G. M., Ortega, E. M. M. and Silva, G.O. (2012). The Kumaraswamy modified Weibull distribution: theory and applications, Journal of Statistical Computation and Simulation, 1-25. 
11. Cordeiro, G. M., Hashimoto, E. M., Ortega, E. M. M. (2014). The McDonald Weibull model, Statistics: A Journal of Theoretical and Applied Statistics, 48, 256-278.

12. Elbatal, I. and Aryal, G. (2013). On the transmuted additive Weibull distribution, Austrian Journal of Statistics , 42, 117-132.

13. Glanzel, W. A. (1987). Characterization theorem based on truncated moments and its application to some distribution families. Mathematical Statistics and Probability Theory (Bad Tatzmannsdorf, 1986), B, Reidel, Dordrecht, 75-84.

14. Glanzel, W. A. (1990). Some consequences of a characterization theorem based on truncated moments. Statistics, 21, 613-618.

15. Gupta, R. C., Gupta, P. L. and Gupta, R. D. (1998). Modeling failure time data by Lehmann alternatives. Communications in Statistics-Theory Methods, 27, 887904.

16. Gupta, R. D. and Kundu, D. (2001). Exponentiated exponential distribution, an alternative to gamma and Weibull distributions. Biometrical Journal , 43, 117 130.

17. Khan, M. N. (2015). The modified beta Weibul distribution, Hacettepe Journal of Mathematics and Statistics, 44, 1553-1568

18. Khan, M. S., and King, R. (2013). Transmuted modified Weibull distribution: A generalization of the modified Weibull probability distribution, European Journal of Pure and Applied Mathematics, 6, 66-88.

19. Kayid, M. and Ahmad, I. (2004). On the mean inactivity time ordering with reliability applications. Probability in the Engineering and Informational Science, $18,395-409$.

20. Kundu, D. and Raqab, M. Z. (2005). Generalized Rayleigh distribution: different methods of estimations. Computational statistics and data analysis, 49, 187-200.

21. Lai, C. D., Xie, M. and Murthy, D. N. P. (2003). A modified Weibull distribution, IEEE Transactions on Reliability, 52, 33-37.

22. Mead, M. E. and Afify, A. Z. (2017). On five-parameter Burr XII distribution: properties and applications. South African Statist. J., 51, 67 -80.

23. Merovci, F. (2013). Transmuted Rayleigh distribution. Austrian Journal of Statistics , 42, 21-31.

24. Mudholkar, G. S., Hutson, A. D. (1996). The exponentiated Weibull family: some properties and a flood data application. Communications in Statistics-Theory and Methods, 25, 3059-3083.

25. Mudholkar, G. S. and Srivastava, D. K. (1993). Exponentiated Weibull family for analyzing bathtub failure-real data, IEEE Transactions on Reliability, 42, 299302.

26. Mudholkar, G. S. and Srivastava, D. K. and Frieme, M. (1995). The exponentiated Weibull family: A reanalysis of the bus-motorfailure data, Technometrics, 37, 436-445. 
27. Mudholkar, G. S. and Srivastava, D. K. and Kollia, G.D. (1996). A generalization of the Weibull distribution with application to the analysis of survival data, Journal of the American Statistical Association, 91, 1575-1583.

28. Nadarajah, S. and Kotz, S. (2006). The exponentiated type distributions, Acta Applicandae Mathematica, 92, 97-111.

29. Navarro, J., Franco, M., and Ruiz, J. (1998). Characterization through moments of the residual life and conditional spacing. The Indian Journal of Statistics, Series A, 60, 36-48.

30. Nofal, Z. M., Afify, A. Z., Yousof, H. M. and Cordeiro, G. M. (2017). The generalized transmuted-G family of distributions, Communications in StatisticsTheory and Methods, 46, 4119-4136.

31. Rayleigh, J. W. S. (1880). On the resultant of a largenumber of vibration of the same pitch and arbitrary phase. Philosophical magazine 5th Series, 10, 73-78.

32. Shaw, W. T. and Buckley, I. R. C. (2007). The alchemy of probability distributions: beyond Gram-Charlier expansions, and a skew-kurtotic-normal distribution from a rank transmutation map. UCL Discovery Repository, pages 116.

33. Silva, G. O., Ortega, E. M. M. and Cordeiro, G. M. (2010). The beta modified Weibull distribution, Lifetime Data Analysis, 16, 409-430.

34. Tian, Y., Tian, M. and Zhu, Q. (2014). Transmuted linear exponential distribution: A new generalization of the linear exponential distribution. Communications in Statistics-Simulation and Computation, 43, 2661-2677.

35. Weibull, W. (1951). A statistical distribution function of wide applicability. Journal of Applied Mechanics, Transactions, 18, 293-297.

36. Xie, M., Tang, Y. and Goh, T. N. (2002). A modified Weibull extension with bathtub failure rate function, Reliability Engineering and System Safety, 76, 279285.

37. Xie, M. and Lai, C. D. (1995). Reliability analysis using an additive Weibull model with bathtub-shaped failure rate function, Reliability Engineering and System Safety, 52, 87-93.

38. Zografos K. and Balakrishnan, N. (2009). On families of beta- and generalized gamma generated distributions and associated inference, Statistical Methodology, 6, 344-362. 